\title{
ОСНОВНЫЕ ТЕНДЕНЦИИ И ФАКТОРЫ СТИМУЛИРОВАНИЯ РАЗВИТИЯ ТУРИСТСКО-РЕКРЕАЦИОННОЙ ОТРАСЛИ РФ НА СОВРЕМЕННОМ ЭТАПЕ *
}

\author{
(C) 2021 Анопченко Татьяна Юрьевна \\ доктор экономических наук, профессор \\ Российский экономический университет имени Г. В. Плеханова, Россия, Москва \\ E-mail: AnopchenkoTY@rae.ru \\ () 2021 Мурзин Антон Дмитриевич \\ доктор технических наук, кандидат экономических наук, доцент \\ Южный федеральный университет, Россия, Ростов-на-Дону \\ Донской государственный технический университет, Россия, Ростов-на-Дону \\ E-mail: admurzin@sfedu.ru \\ (c) 2021 Ревунов Роман Вадимович \\ кандидат экономических наук, доцент \\ Южный федеральный университет, Россия, Ростов-на-Дону \\ E-mail:rrevunov@sfedu.ru \\ (c) 2021 Лапин Александр Сергеевич \\ аспирант \\ Южный федеральный университет, Россия, Ростов-на-Дону \\ E-mail: lapia8@gmail.com
}

В статье представлена динамика валовой добавленной стоимости, создаваемой туристской индустрией РФ, а также основных показателей развития туристской отрасли в РФ за период 2014-2020 гг., отражён вклад туризма в валовой внутренний продукт РФ, аргументированы организационно-экономические и нормативно-правовые инструменты стимулирования платёжеспособного спроса граждан РФ на производимые в стране турпродукты, изложен прогнозируемый социально-экономический эффект, возникающий вследствие реализации предлагаемых мероприятий.

Ключевые слова: туризм, развитие, экономика, Россия, отрасль, механизм, инструменты, регулирование.

Наблюдаемая в настоящее время рецессия российской экономики, отягощаемая негативными последствиями пандемии коронавирусной инфекции, актуализирует научный поиск решений, направленных на стимулирование развития отраслей экономики Российской Федерации. В связи со сказанным, не вызывает сомнений своевременность исследований, направленных на разработку организационноэкономического и нормативно-правового стимулирования туристско-рекреационной сферы РФ.

На современном этапе в РФ представлены все основные виды современного туризма: познавательный, оздоровительный, гастрономический, спортивный, деловой и т.д. Основны- ми районами страны, обладающими развитой туристско-рекреационной инфраструктурой и воспринимающими большую часть турпотока, являются южно-российский макрорегион, города Санкт-Петербург, Москва [2, 3]. Туристскорекреационный экономический комплекс вносит существенный вклад в производство валового внутреннего продукта РФ (рисунок 1 [7]).

Как показывают данные рисунка 1 , за период с 2015 по 2019 гг. наблюдается рост валовой добавленной стоимости, создаваемой туристской индустрией РФ. Положительная динамика составляет 1423,2 млрд. руб. (+58,2\%). Столь существенный рост обусловлен действием ряда факторов, в частности: значительными капиталовложениями в развитие туристско-

* Исследование выполнено при финансовой поддержке РФФИ в рамках научного проекта № 20010-00820 


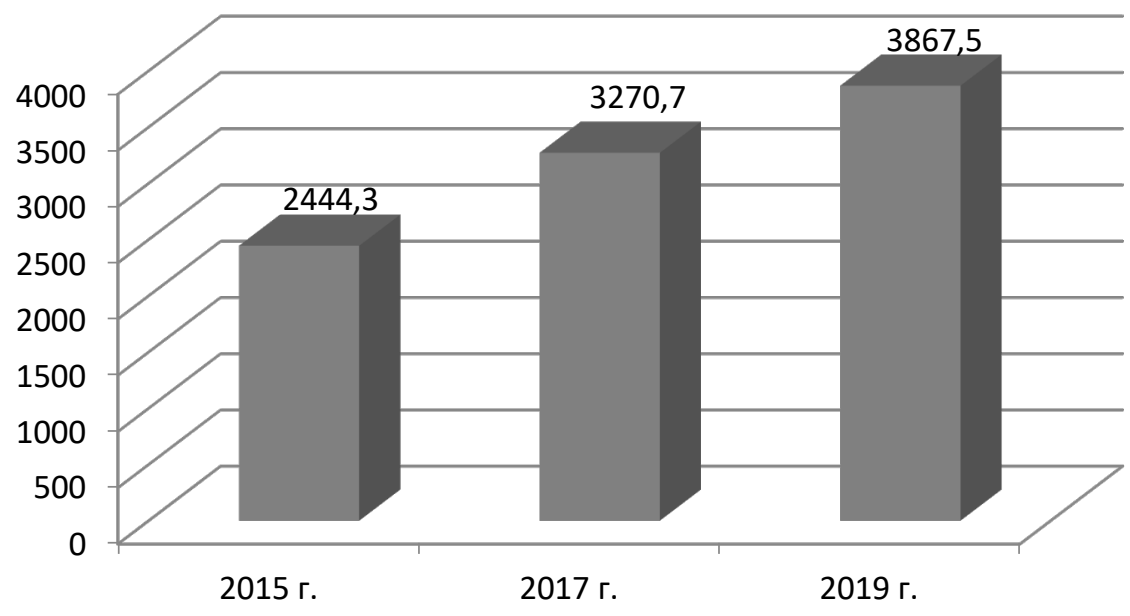

Валовая добавленная стоимость туристской индустрии РФ, млрд руб.

Puc. 1. Динамика валовой добавленной стоимости, создаваемой туристской индустрией РФ за период 2015-2019 г, млрд руб. (в сопоставимых ценах)

рекреационной инфраструктуры Сочи в связи с проведением XXII Олимпийских игр, а также Чемпионата мира по футболу 2018 г.; повышением разнообразия и улучшением качества производимых в РФ туристско-рекреационных продуктов. Указанные факторы способствовали повышению вклада туризма в валовой внутренний продукт РФ с 3,3\% в 2015 г. до 3,9\% в 2019 г. $(+0,6 \%)$. Графическая интерпретация данного процесса представлена на рисунке 2 [7].

Рассмотрим основные показатели развития туристской отрасли в РФ за период 2014-2020 гг. (таблица 1 [7]).

Представленная в таблице 1 информация свидетельствует о том, что за период 20142017 гг. в РФ наблюдалось устойчивое развитие туристско-рекреационной сферы. Основные экономические показатели отрасли демонстрировали устойчивый рост (за исключением инвестиций в основной капитал коллективных средств размещения, сократившихся с 80468,5 млн. руб. в 2014 г. до 35483,4 млн. руб. в 2017 г. (-44985,1 млн. руб.). Однако за период 2017-2020 гг. наблюдается резкое ухудшение

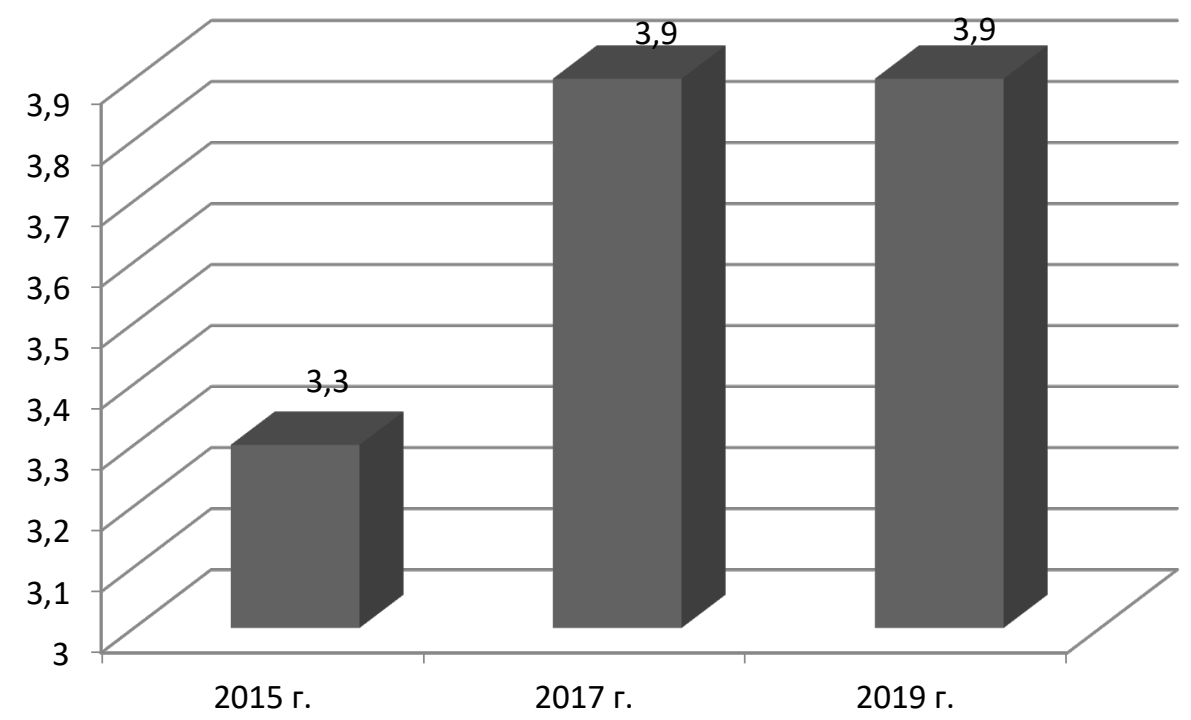

Вклад туризма в ВВП РФ, \%

Puc. 2. Вклад туризма в валовой внутренний продукт РФ за период 2015-2019 гг., \% (в сопоставимых ценах) 
Таблиц̧а 1. Основные показатели развития туристской отрасли в РФ за период 2014-2020 гг. м(в сопоставимых ценах)

\begin{tabular}{|l|c|c|c|c|c|}
\hline \multicolumn{1}{|c|}{ Показатель } & \multicolumn{3}{|c|}{ Годы } & \multicolumn{2}{|c|}{ Динамика } \\
\cline { 2 - 5 } & 2014 & 2017 & 2020 & $\begin{array}{c}\text { в абс. } \\
\text { 3наченях }\end{array}$ & в \% \\
\hline $\begin{array}{l}\text { Количество граждан РФ, принятых в коллективных } \\
\text { средствах размещения, млн. чел. }\end{array}$ & 33,8 & 53,5 & 46,2 & 12,4 & 36,7 \\
\hline $\begin{array}{l}\text { Количество граждан иностранных государств, приня- } \\
\text { тых в коллективных средствах размещения РФ, млн. } \\
\text { чел. }\end{array}$ & 4,6 & 8,0 & 2,2 & $-2,5$ & $-53,1$ \\
\hline $\begin{array}{l}\text { Инвестиции в основной капитал коллективных } \\
\text { средств размещения (гостиницы, места для временно- } \\
\text { го проживания), млн. руб. }\end{array}$ & 80468,5 & 32483,4 & 46691,2 & $-33777,3$ & $-42,0$ \\
\hline $\begin{array}{l}\text { Потребление туристско-рекреационных продуктов в } \\
\text { РФ, млрд. руб. }\end{array}$ & 147,5 & 166,5 & 91,9 & $-55,6$ & $-37,7$ \\
\hline $\begin{array}{l}\text { Платные услуги гостиниц, иных средств размещения, } \\
\text { млрд. руб. }\end{array}$ & 175,7 & 219,9 & 181,6 & 5,9 & 3,4 \\
\hline
\end{tabular}

основных показателей экономического развития, обусловленное негативным воздействием пандемии коронавирусной инфекции. Вместе с тем, если рассматривать изменение ситуации в течение более длительного временного интервала, например, с 2014 по 2020 г., можно выявить противоречивые тенденции. В частности, по такому показателю, как количество граждан РФ, принятых в коллективных средствах размещения, отмечается положительная динамика, составившая за период наблюдения 12,4 млн. чел. $(+36,7)$. В тоже время, аналогичный показатель для граждан иностранных государств демонстрирует снижение на 2,5 млн. чел (-53,1\%). Потребление туристско-рекреационных продуктов в РФ упало за период 2014-2020 г. на 55,6 млрд. руб. (-37,7\%), однако объём продаж услуг гостиниц, иных средств размещения увеличился на 5,9 млрд. руб. (+3,4\%).

Согласно научной позиции авторов, разнонаправленный характер выявленных тенденций свидетельствует об определённом запасе прочности, накопленном российской туристскорекреационной отраслью, позволяющем преодолеть ограничения на перемещения граждан, введённые государственными органами разных стран в связи с пандемией коронавируса.

Рассмотрим возможные организационноэкономические и нормативно-правовые меры, способствующие ускорению развития туризма в РФ. По нашему мнению, одним из возможных инструментов смягчения негативных последствий пандемии коронавирусной инфекции для туристско-рекреационной сферы может быть стимулирование платёжеспособного спроса на производимые в РФ туристско-рекреационные продукты. Практическая реализация предлагаемой меры подразумевает расширение оснований, предусмотренных статьёй 219 Налогового кодекса РФ [6], для получения социального налогового вычета в размере 50 тыс. руб. Среди вновь вводимых оснований необходимо указать приобретение физическим лицом - налогоплательщиком (или его законными представителями в случаях недееспособности гражданина (в т.ч., в отношении несовершеннолетних граждан)) туристско-рекреационного продукта [8] сделанного на территории РФ. Реализация указанной меры позволит сформировать механизм возмещения части расходов домохозяйств, связанных с приобретением туристско-рекреационных продуктов, а также позволит переориентировать часть турпотока на внутрироссийские направления. Прогнозируемые социально экономические последствия заключаются в следующем:

- возрастает платёжеспособный спрос на туристско-рекреационные продукты, создаваемые на территории РФ, что способствует росту доходности туриндустрии, сокращению периодов окупаемости реализуемых в данной отрасли инвестиционных проектов;

- возрастает загруженность объектов размещения туристов на территории РФ, смягчаются межсезонные колебания туристического потока;

- увеличивается количество рабочих мест в туристско-рекреационной отрасли РФ;

- возрастают налоговые отчисления в бюджетную систему РФ, поступающие от хозяйствующих субъектов туристско-рекреационной отрасли. 
С высокой степенью вероятности можно предполагать сохранение в среднесрочной перспективе (2-3 года) ограничений на передвижение, обусловленных пандемией коронавирусной инфекции. В связи с этим, является актуальной задачей поиск новых форматов создания и продвижения туристско-рекреационных продуктов на рынке. Использование цифровых технологий способствует смягчению негативные последствия пандемии. В частности, в рамках реализации организационно-экономических мер по региональному брендированию, представляется целесообразным создание цифрового контента (фильмов, виртуальных туров, экскурсий, интерактивных приложений и т.п.), отражающего туристско-рекреационные предложения соответствующего региона или муниципального образования РФ $[1,4]$. Продвижение данного контента может осуществляться в комбинированной форме, сочетающей бесплатный и платный доступ к познавательной информации. Среди компонентов прогнозируемого социально-экономического эффекта выделим следующие:

- повышение узнаваемости бренда территории;

- расширение аудитории потребителей цифровых туристических продуктов;

- формирование источника дополнительных доходов хозяйствующих субъектовправообладателей цифровых туристических продуктов.

Дополнительным фактором повышения эффективности цифрового инструментария в туристско-рекреационной сфере является мультиязыковая поддержка, позволяющая существенно расширить аудиторию потребителей за пределами Российской Федерации.

Подводя итог сказанному, сформулируем следующие основные выводы:

1. Согласно данных Всемирной туристической организации туризм является одной из наиболее динамично развивающихся отраслей мировой экономики. Согласно результатов исследований [9, 10], за период с 1990-го по 2020 г. в мире наблюдается удвоение количества потребителей туристско-рекреационных услуг. Среди базовых макроэкономических факторов, способствующих дальнейшему развитию подобной тенденции, необходимо выделить рост глобальной экономики, сопровождающийся постепен- ным повышением уровня благосостояния; развитие глобальной транспортно-логистической инфраструктуры, что способствует относительному удешевлению перевозок пассажиров. В связи со сказанным, является необходимой продуманная государственная политика развития туристско-рекреационной отрасли РФ, позволяющая эффективно позиционировать и продвигать создаваемые в нашей стране туристскорекреационные продукты на мировом рынке.

2. Пандемия коронавирусной инфекции, одним из следствий которой являются применяемые в глобальном масштабе ограничения передвижения граждан, нанесла значительный урон развитию туризма и рекреации как в мире, в целом, так и в Российской Федерации, в частности. Вместе с тем, по нашему мнению, основные последствия пандемии будут преодолены в среднесрочной перспективе (2-3 года), соответственно, устранятся ограничения на передвижения граждан в связи с выработкой коллективного иммунитета, вакцинацией и реализацией других противопандемических мер. С высокой степенью вероятности можно прогнозировать широкомасштабную трансформацию мирового рынка туристско-рекреационных услуг. Российская Федерация, располагающая уникальным природным потенциалом, богатой историей и культурой имеет возможность стать одним из ключевых игроков на глобальном туристическом рынке.

3. Одним из факторов преодоления наблюдаемой в настоящее время в РФ экономической рецессии, является развитие туристко-рекреационной отрасли. Предлагаемые нами организационно-экономические и административно-правовые меры направлены на формирование устойчивого внутреннего платёжеспособного спроса на изготовленные в РФ турпродукты, повышение эффективности экономической деятельности в сфере туризма и рекреации РФ, смягчение межрегиональных диспропорций социально-экономического развития, усиление конкурентных преимуществ туристско-рекреационного комплекса РФ. Прогнозируемый социально-экономический эффект является мультипликативным, генерирующим позитивные импульсы развития не только в сфере туризма, но и в других отраслях и видах экономической деятельности РФ, в частности, транспортно-логистическом. 


\section{Библиографический список}

1. Анопченко Т.Ю. Подходы к оценке эффективности управления туристско-рекреационной деятельностью на микро- и мезоэкономическом уровнях / Анопченко Т.Ю., Мурзин А.Д., Ревунов Р.В. // Региональные проблемы преобразования экономики. 2020. № 3 (113). С. 130-135. DOI: 10.26726/1812-7096-2020-03-130135

2. Анопченко Т.Ю. Туристско-рекреационный потенциал Юга России и организационно-экономические инструменты его развития / Анопченко Т. Ю., Минатуллаев А.А., Ревунов Р.В.// Московский экономический журнал. 2020. № 10. С. 53.

3. Анопченко Т.Ю. Направления повышения эффективности использования туристско-рекреационного потенциала республики Крым в контексте критериев устойчивого развития / Анопченко Т. Ю., Мурзин А.Д., Ревунов Р.В.// Региональные проблемы преобразования экономики. 2019. № 7 (105). С. 108-114.

4. Лапин А. С. Цифровая трансформация туристической деятельности: лучшие мировые практики / Цифровое пространство: экономика, управление, социум: сборник статей по материалам III Всероссийской научной конференции (г. Смоленск, СмолГУ, 25 июня 2021 г.) - Смоленск: СмолГУ, 2021, -166 с.

5. Майданевич Ю.П. Анализ системы государственного воздействия на предпринимательскую активность в туристско-рекреационном комплексе региона // Экономика и предпринимательство 2021. № 5 (130). С. 497-502. (ВАК) DOI: 10.34925/EIP.2021.130.5.095

6. Налоговый кодекс Российской Федерации часть 2 (НК РФ ч. 2) от 5 августа 2000 г. № 117-Ф3

7. Официальный сайт Федерального агентства по туризму РФ https:/tourism.gov.ru/contents/analytics/ statistics/statisticheskie-pokazateli-kharakterizuyushchie-razvitie-turistskoy-otrasli-v-rossiyskoy-federatsii-/ дата обращения 26 ноября 2021 г.

8. Федеральный закон от 24 ноября 1996 г. № 132-Ф3 «Об основах туристской деятельности в Российской Федерации»

9. Official website of the United Nations Environment Program (UNEP). Available at: http://www.unep.org/ resourceefficiency/Home/Business/SectoralActivities/Tourism/tabid/78766/Default.aspx [accessed: September 16, 2021]

10. Official website of the UN World Tourism Organization Available at: https://www.unwto.org/tourism-flowssource-markets-and-destinations [accessed: September 16, 2021] 